\title{
Pseudolaric acid $B$ activates autophagy in MCF-7 human breast cancer cells to prevent cell death
}

\author{
JINGHUA YU ${ }^{1}$, CHUNHAI CHEN $^{2}$, TIANYANG XU ${ }^{3}$, MINGHUI YAN $^{4}$, BIANBIAN XUE $^{5}$, YING WANG $^{5}$, \\ CHUNYU LIU ${ }^{2}$, TING ZHONG ${ }^{6}$, ZENGYAN WANG ${ }^{7}$, XIANYING MENG $^{8}$, DONGHUA HU $^{6}$ and XIAOFANG YU ${ }^{1,9}$ \\ ${ }^{1}$ Institute of Virology and AIDS Research, The First Hospital of Jilin University, Changchun, Jilin 130021; \\ ${ }^{2}$ Department of Acupunture, The Affiliated Hospital of Changchun University of Chinese Medicine, Changchun, Jilin 130000; \\ ${ }^{3}$ Department of Drug Analysis and Analytical Chemistry, Changchun University of Chinese Medicine, Changchun, \\ Jilin 130117; ${ }^{4}$ Department of Biomedical Engineering, College of Pharmacy, Jilin University, Changchun, Jilin 130000; \\ ${ }^{5}$ Department of Gastroenterology, The First Hospital of Jilin University, Changchun, Jilin 130021; \\ ${ }^{6}$ Department of Medicinal Chemistry, Changchun University of Chinese Medicine, Changchun, Jilin 130117; \\ ${ }^{7}$ Department of Internal Medicine, The First Hospital of Jilin University, Changchun, Jilin 130000; \\ ${ }^{8}$ Department of Thyroid Surgery, The First Hospital of Jilin University, Changchun, Jilin 130021, P.R. China; \\ ${ }^{9}$ Department of Molecular Microbiology and Immunology, Johns Hopkins Bloomberg School of Public Health,
} Baltimore, MD 21205, USA

Received September 3, 2014; Accepted November 24, 2015

DOI: 10.3892/ol.2016.4103

\begin{abstract}
Pseudolaric acid B (PAB) has been demonstrated to exert antitumor effects in MCF-7 human breast cancer cells. The present study aimed to investigate the mechanism of resistance to PAB-induced cell death. Following incubation with $4 \mu \mathrm{M}$ of PAB for 3 days, the majority of MCF-7 cells became senescent, while some retained the same morphology as control cells, as assessed using a senescence detection kit. Additionally, $36 \mathrm{~h}$ of treatment with $4 \mu \mathrm{M}$ of PAB increased the positive staining of autophagy markers, as shown by monodansylcadaverine and acridine orange staining. Western blot analysis indicated that this treatment also increased expression of the autophagy-related proteins Beclin-1 and microtubule-associated protein 1 light chain 3. Furthermore, treatment with PAB and the autophagy inhibitor 3-methyl adenine significantly decreased the ratio of autophagy, as assessed by flow cytometric analysis of monodansylcadaverine staining density $(\mathrm{P}<0.001)$, and increased the ratio of cell death, as assessed by MTT analysis $(\mathrm{P}<0.001)$. This indicated that autophagy promotes cell survival as a resistance mechanism to
\end{abstract}

Correspondence to: Professor Xiaofang Yu, Institute of Virology and AIDS Research, The First Hospital of Jilin University, 519 Dongming Zhu Street, Changchun, Jilin 130021, P.R. China E-mail: xfyu@jhsph.edu

Professor Donghua Hu, Department of Medicinal Chemistry, Changchun University of Chinese Medicine, Laboratory Building, 1035 Boshuo Road, Changchun, Jilin 130117, P.R. China

E-mail: 497573398@qq.com

Key words: autophagy, MCF-7 human breast cancer cells, pseudolaric acid B
PAB treatment. Additionally, the present study demonstrated that PAB treatment did not affect the mitochondrial membrane potential, which may be related to autophagy. Increased Bcl-2 expression may explain why PAB did not affect the mitochondrial membrane potential. A Bcl-2 binding test demonstrated that PAB treatment inhibits the binding of Bcl-2 and Beclin-1, which may free Beclin-1 to participate in autophagy. Therefore, the present study demonstrated that autophagy may be activated by PAB treatment in human breast cancer MCF-7 cells, contributing to resistance to cell death.

\section{Introduction}

Pseudolaric acid B (PAB) is a diterpene acid isolated from the root and trunk bark of Pseudolarix kaempferi Gord. (Pinaceae; also known as Tu Jing Pi in traditional Chinese medicine), and has been used to treat dermatological fungal infections (1). PAB exerts potent antifungal (1), antifertility (2) and cytotoxic activities in vitro (3). Breast cancer is the most common invasive cancer in women worldwide. Surgery, medication and radiation may be used in the treatment of breast cancer; thus it typically has a favorable prognosis $(4,5)$. Our previous study demonstrated that treatment of MCF-7 human breast cancer cells with PAB led to the induction of mitotic arrest and apoptosis in the majority of cells, while the surviving cells became senescent (6); however, the mechanism by which these cells were directed towards either cell death or survival has not yet been determined.

Programmed cell-death may be achieved through two distinct processes (7). Apoptosis (type I) is typically characterized by a series of morphological events, including cell shrinkage, DNA fragmentation and the formation of membrane-bound apoptotic bodies that are rapidly phagocytosed by neighboring cells (8). By contrast, autophagy (type II), which may contribute to cell death or cell survival, 
is characterized by the appearance of autophagosomes that engulf bulk cytoplasm and cytosolic organelles, such as mitochondria and endoplasmic reticulum. Lysosomes fuse with the autophagic vesicles, leading to degradation of their cargo. Autophagy recycles cellular material for survival; however, its continuation leads to organelle degradation and ultimately cell death (9-13). The association between autophagy and apoptosis is complex and varies between different cell types and cellular stress conditions. Autophagy and apoptosis may facilitate or inhibit each other to execute alternative functions in the cell (14-16).

The present study aimed to elucidate the role of autophagy in PAB-induced cell death in the MCF-7 cell line prior to the onset of cellular senescence.

\section{Materials and methods}

Materials. PAB and dracorhodin perchlorate (DP; a synthetic analogue of the antimicrobial anthocyanin red pigment dracorhodin, used as positive control for mitochondrial membrane analysis) were purchased from the National Institute for the Control of Pharmaceutical and Biological Products (Beijing, China) and dissolved in dimethyl sulfoxide (DMSO) to create stock solutions $(10 \mathrm{mM})$. The DMSO concentration was maintained at $<0.1 \%$ in all cell cultures and did not exert any detectable effect on cell growth. The Senescence Detection Kit was purchased from EMD Millipore (Billerica, MA, USA). 3-(4,5-dimethylthiazol-2-yl)-2,5-diphenyltetrazolium bromide (MTT), monodansylcadaverine (MDC), acridine orange, rhodamine 123, and 3-methyladenine (3-MA) were purchased from Sigma-Aldrich (St. Louis, MO, USA). Polyclonal rabbit anti-human Beclin-1 (\#11306-1-AP) and B-cell lymphoma 2 (Bcl-2; \#12789-1-AP) IgG antibodies, and monoclonal mouse anti-human microtubule-associated protein 1 light chain 3 (LC3) IgG $_{1}$ antibody (\#66139-1-Ig) were purchased from ProteinTech Group, Inc. (Chicago, IL, USA). Monoclonal mouse anti-human $\beta$-actin (\#sc-8432) and $\alpha$-tubulin (\#sc-23948) $\operatorname{IgG}_{1}$, and alkaline phosphatase (AP)-labelled rabbit anti-mouse (\#sc-358915) and goat anti-rabbit (\#sc-2057) IgG antibodies were obtained from Santa Cruz Biotechnology, Inc. (Santa Cruz, CA, USA). Protein A Sepharose CL-4B was purchased from GE Healthcare Life Sciences (Tokyo, Japan).

Cell culture. MCF-7 human breast cancer cells were obtained from the American Type Culture Collection (Manassas, VA, USA). The cells were cultured in RPMI-1640 medium (GE Healthcare Life Sciences, Logan, UT, USA) supplemented with $10 \%$ fetal calf serum (heat-inactivated, $56^{\circ} \mathrm{C}$ for $30 \mathrm{~min}$ ), $2 \mathrm{mM}$ glutamine (both Gibco; Thermo Fisher Scientific, Carlsbad, CA, USA), penicillin (100,000 U/1; Sigma-Aldrich) and streptomycin (100 mg/l; Amresco, Solon, OH, USA), and maintained at $37^{\circ} \mathrm{C}$ in a $5 \% \mathrm{CO}_{2}$ humidified atmosphere. Cells were treated with various concentrations of PAB dissolved in DMSO, with a final DMSO concentration $<0.1 \%$, or with DMSO alone. DMSO-treated cells were used as a control. PAB doses and incubation times were selected based on a previous study (6).

Senescence-associated (SA)- $\beta$-galactosidase detection. The MCF-7 cells $\left(1.5 \times 10^{5}\right.$ cells/well) were seeded into 24 -well culture plates (Nalge Nunc International, Penfield, NY, USA).
Following incubation overnight, $4 \mu \mathrm{M}$ PAB was added and the plates were incubated for 3 days. The senescence detection kit was used according to the manufacturer's instructions, as previously described (6). Finally, the cells were observed under a phase contrast microscope (Olympus IX51; Olympus Corporation, Tokyo, Japan) for the development of a blue color.

MDC staining observed by fluorescence microscopy and flow cytometry. The fluorescent compound MDC is used as a tracer for autophagic vacuoles (17), and 3-MA is the most commonly used inhibitor of autophagic sequestration (18). MCF-7 cells $\left(6 \times 10^{5}\right.$ cells/well) were seeded into 6 -well culture plates (Nunc, Denmark). Following overnight incubation, the cells were treated with $4 \mu \mathrm{M}$ PAB and/or $3 \mathrm{mM}$ 3-MA for $36 \mathrm{~h}$, and subsequently incubated with $0.05 \mathrm{mM}$ $\mathrm{MDC}$ at $37^{\circ} \mathrm{C}$ for $1 \mathrm{~h}$. Following incubation, the cells were washed once with phosphate-buffered saline (PBS). Intracellular MDC was observed by fluorescence microscopy at an excitation wavelength of $380 \mathrm{~nm}$ with an emission filter of $525 \mathrm{~nm}$ (Olympus CKX31; Olympus Corporation) and analyzed using a FACScan flow cytometer (BD Biosciences, Franklin Lakes, NJ, USA).

Autophagy observed by acridine orange staining. MCF-7 cells $\left(6 \times 10^{5}\right.$ cells/well) were seeded into 6 -well culture plates containing $18 \times 18-\mathrm{mm}$ coverslips, and treated with 0 or $4 \mu \mathrm{M}$ PAB for $36 \mathrm{~h}$, then rinsed and stained with acridine orange $(10 \mathrm{mg} / \mathrm{l})$ at $37^{\circ} \mathrm{C}$ for $30 \mathrm{~min}$. After the coverslips were mounted, the samples were observed using a fluorescence microscope (Olympus CKX31; Olympus Corporation) to assess the color change from green to red.

Cell growth inhibition assay. Inhibition of cell growth was determined using an MTT assay. MCF-7 cells $\left(1.5 \times 10^{4}\right.$ cells/well) were seeded into 96 -well culture plates (Nalge Nunc International). Following incubation overnight, $4 \mu \mathrm{M}$ PAB and/or $3 \mathrm{mM} 3$-MA were added to the plates After an incubation of $36 \mathrm{~h}$, cell growth was measured by further incubation with MTT solution at $37^{\circ} \mathrm{C}$ for $3 \mathrm{~h}$, followed by the addition of DMSO $(150 \mu \mathrm{l})$ to dissolve the formazan crystals. Absorbance was measured at $492 \mathrm{~nm}\left(\mathrm{~A}_{492}\right)$ with an enzyme-linked immunosorbent assay plate reader iMark $^{\mathrm{TM}}$ Microplate Reader; Bio-Rad Laboratories Inc., Hercules, CA, USA). The percentage of inhibition was calculated as follows: Cell death $(\%)=\mathrm{A}_{492}[($ control - sample $) /$ control $] \times 100 \%$.

Observation of morphological changes by light microscopy. MCF-7 cells were treated with PAB $(0,1,4$ or $8 \mu \mathrm{M})$ and/or 3-MA (3 mM) for $36 \mathrm{~h}$. The morphological changes were observed by phase contrast microscopy (Olympus IX51; Olympus Corporation).

Western blot protein expression analysis. MCF-7 cells were treated with $4 \mu \mathrm{M}$ PAB for $36 \mathrm{~h}$, and adherent and floating cells were collected and stored at $-80^{\circ} \mathrm{C}$. Western blot analysis was performed for the total proteins, as previously described (19). Cells were lysed directly in sodium dodecyl sulfate (SDS) sample buffer (60 mM Tris-HCl, pH 6.8; 2\% SDS; $10 \%$ glycerol; 5\% 2-mercaptoethanol; $0.01 \%$ bromophenol blue), followed by boiling for $10 \mathrm{~min}$. Whole-cell lysates were 

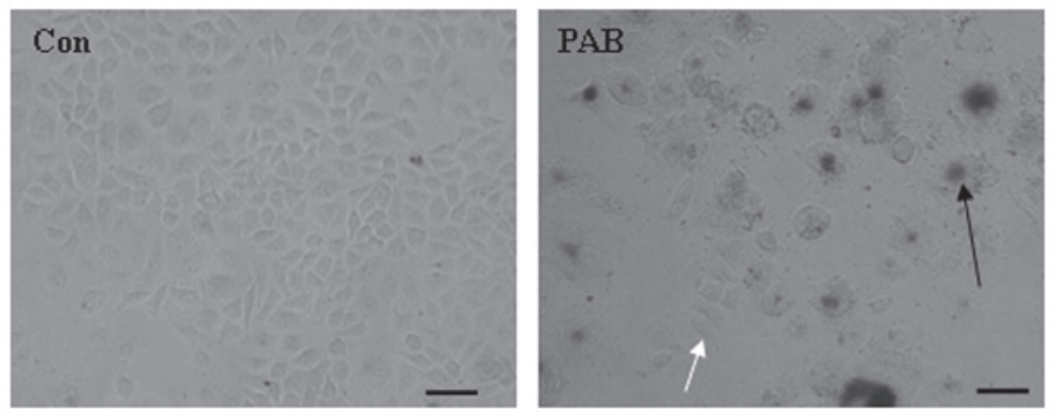

Figure 1. PAB did not kill all tumor cells after 3 days. MCF-7 cells were treated with $4 \mu \mathrm{M}$ PAB for 3 days and subsequently stained with SA- $\beta$-galactosidase, a marker of senescence. PAB induced partial cell senescence and partially affected cell growth compared with the Con group. The experiments were performed in triplicate. Black arrow indicates senescent cells; white arrow indicates cells with normal morphology. Scale bar, $45 \mu \mathrm{m}$. PAB, pseudolaric acid B; Con, control.

further subjected to SDS-polyacrylamide gel electrophoresis. Proteins were transferred to nitrocellulose membranes (Bio-Rad Laboratories, Inc.) and detected with corresponding primary antibodies against LC3A/B (dilution, 1:500); Beclin-1 antibody $(1: 1,000)$, Bcl-2 antibody $(1: 1,000), \beta$-actin antibody $(1: 2,000)$, and $\alpha$-Tubulin antibody $(1: 2,000)$, incubated overnight at $4^{\circ} \mathrm{C}$. Subsequently, the membranes were incubated with AP-conjugated anti-mouse or anti-rabbit secondary antibodies $(1: 1,000)$ for $2 \mathrm{~h}$ at room temperature. The membranes were then reacted with 5-bromo-4-chloro-39-indolylphosphate and nitro-blue tetrazolium substrate (Sigma-Aldrich).

Mitochondrial membrane potential analysis by rhodamine 123 staining. MCF-7 cells were harvested and rinsed with PBS. The cells were then stained with $5 \mu \mathrm{g} / \mathrm{ml}$ of rhodamine 123 at $37^{\circ} \mathrm{C}$ for $30 \mathrm{~min}$. Following incubation, the cells were washed once with PBS. The intensity of rhodamine 123 staining was observed by fluorescence microscopy at an excitation wavelength of $505 \mathrm{~nm}$ with an emission filter of $534 \mathrm{~nm}$ (Olympus CKX31; Olympus Corporation) and analyzed using a FACScan flow cytometer.

Immunoprecipitation analysis of $\mathrm{Bcl}-2$ protein complexes. MCF-7 cells $\left(1 \times 10^{6}\right.$ cells/bottle) were cultured in a $25-\mathrm{ml}$ culture bottle overnight. Subsequently, the cells were treated with $4 \mu \mathrm{M}$ PAB for $36 \mathrm{~h}$. Immunoprecipitation analysis was conducted as described in a previous study (20). Briefly, radioimmunoprecipitation assay buffer $[50 \mathrm{mM}$ Tris- $\mathrm{HCl} ; 1 \%$ NP-40; $0.25 \%$ sodium deoxycholate; $150 \mathrm{mM} \mathrm{NaCl} ; 1 \mathrm{mM}$ EDTA; $1 \mathrm{mM}$ phenylmethylsulfonylfluoride; $1 \mathrm{mM}$ sodium orthovanadate $\left(\mathrm{Na}_{3} \mathrm{VO}_{4}\right) ; 1 \mathrm{mM} \mathrm{NaF} ; 1 \mu \mathrm{g} / \mathrm{ml}$ aprotinin; $1 \mu \mathrm{g} / \mathrm{ml}$ leupeptin; $1 \mu \mathrm{g} / \mathrm{ml}$ pepstanin] was used for cell lysis. Subsequently, Bcl-2 antibody (dilution, 1:100) was added to precipitate $\mathrm{Bcl}-2$ and the Bcl-2-binding protein Beclin-1 with Protein A Sepharose beads. Finally western blotting was used to analyze the expression of Bcl-2 and Beclin-1 (dilution, 1:1,000).

Statistical analysis. All data represent at least three independent experiments and are expressed as the mean \pm standard deviation. Statistical comparisons were performed using the Student's t-test through Microsoft Excel 2007 (Microsoft, Franklin, TN, USA. P<0.05 was considered to represent a statistically significant difference.

\section{Results}

$P A B$ does not induce complete tumor cell death over a period of 3 days. MCF-7 cells were treated with $4 \mu \mathrm{M}$ PAB for 3 days and senescence was monitored using a senescence detection kit. The results of this assay demonstrated that larger cells were positive (Fig. 1, black arrow) for the senescence marker SA- $\beta$-galactosidase, indicating that larger cells became senescent following PAB treatment. In addition, a number of cells retained a similar morphology to control cells and stained negative for SA- $\beta$-galactosidase (Fig. 1). Therefore, a number of MCF-7 cells were able to resist PAB-induced cell death and senescence at this time point.

$P A B$ induces autophagy. Previous studies have demonstrated that PAB treatment induces apoptosis in breast cancer cells $(3,6,21)$. However, the present study demonstrated that certain cells survived treatment with PAB, therefore, the mechanism by which cell survival is promoted following PAB treatment was investigated. Western blot analysis of MCF-7 cells following $36 \mathrm{~h}$ of PAB treatment revealed increased protein expression of Beclin-1 and enhanced conversion of LC3-I to LC3-II (Fig. 2A). Fluorescence microscopy of PAB-treated MCF-7 cells demonstrated the appearance of bright green dots from MDC staining and a color change from green to red following acridine orange staining, compared with the untreated control group at $36 \mathrm{~h}$ (Fig. 2B and C). Therefore, $\mathrm{PAB}$ induced autophagy in MCF-7 cells.

Autophagy promotes cell survival. At $36 \mathrm{~h}$, the autophagic ratio of PAB-treated cells was $35.30 \pm 4.12 \%$; however, in combination with 3-MA treatment, the autophagic ratio of PAB-treated cells was $14.87 \pm 3.73 \%$ ( $\mathrm{P}<0.001$; Fig. $3 \mathrm{~A}$ ). The MTT assay demonstrated that the apoptotic ratio of PAB-treated cells was $43.56 \pm 4.36 \%$; while the apoptotic ratio of $\mathrm{PAB}$ and $3-\mathrm{MA}$-treated cells was $76.12 \pm 6.46 \%$ $(\mathrm{P}<0.001$; Fig. 3B). Therefore, 3-MA significantly increased the inhibitory effect of PAB. To confirm the results, morphological changes were observed by phase contrast microscopy. A decrease in the total cell number, an increase in floating cells, and the appearance of apoptotic bodies were observed at $36 \mathrm{~h}$ after $4 \mu \mathrm{M}$ PAB treatment. PAB and 3-MA combination treatment resulted in a further decrease in the total cell number, and a further increase in the number of floating 
A
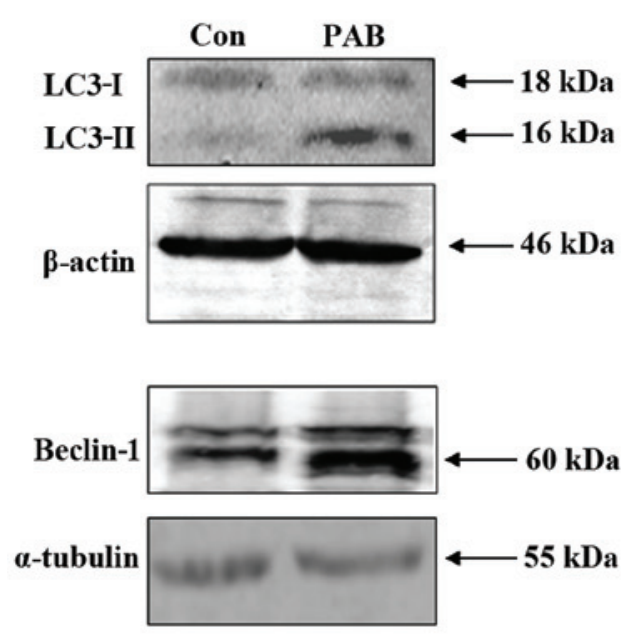

B
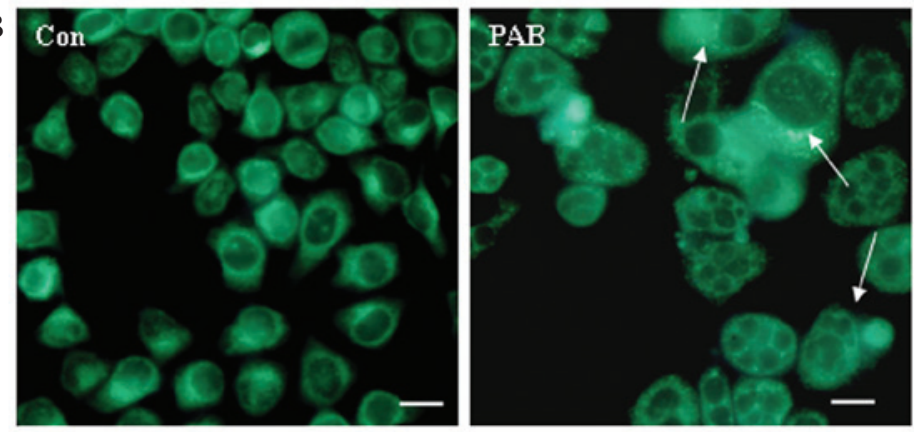

C
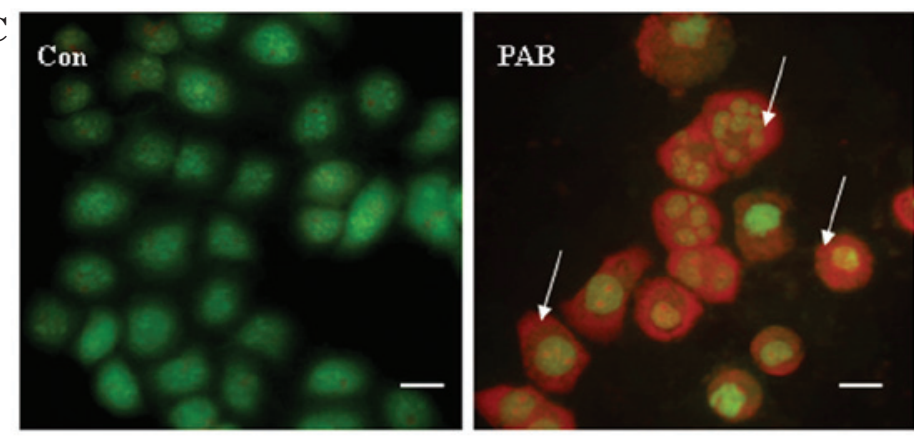

Figure 2. Autophagy was induced in MCF-7 cells at $36 \mathrm{~h}$ following PAB $(4 \mu \mathrm{M})$ treatment. (A) Expression of LC3-I, LC3-II and Beclin-1 was detected by western blot analysis, using $\beta$-actin/ $\alpha$-tubulin as the loading control. PAB was found to promote the conversion from LC3-I to LC3-II, and to increase the expression of Beclin-1 compared with the Con group. (B) Monodansylcadaverine staining of autophagic vacuoles, revealing that PAB increased the number of autophagic vacuoles compared with the Con group (arrows indicate positive staining; scale bar, $15 \mu \mathrm{m}$ ). (C) Acridine orange staining, revealing that PAB increased the number of autophagic vacuoles compared with the Con group (arrows indicate red positive staining; scale bar, $15 \mu \mathrm{m}$ ). All experiments were performed in triplicate. PAB, pseudolaric acid B, LC3, light chain 3; Con, control.
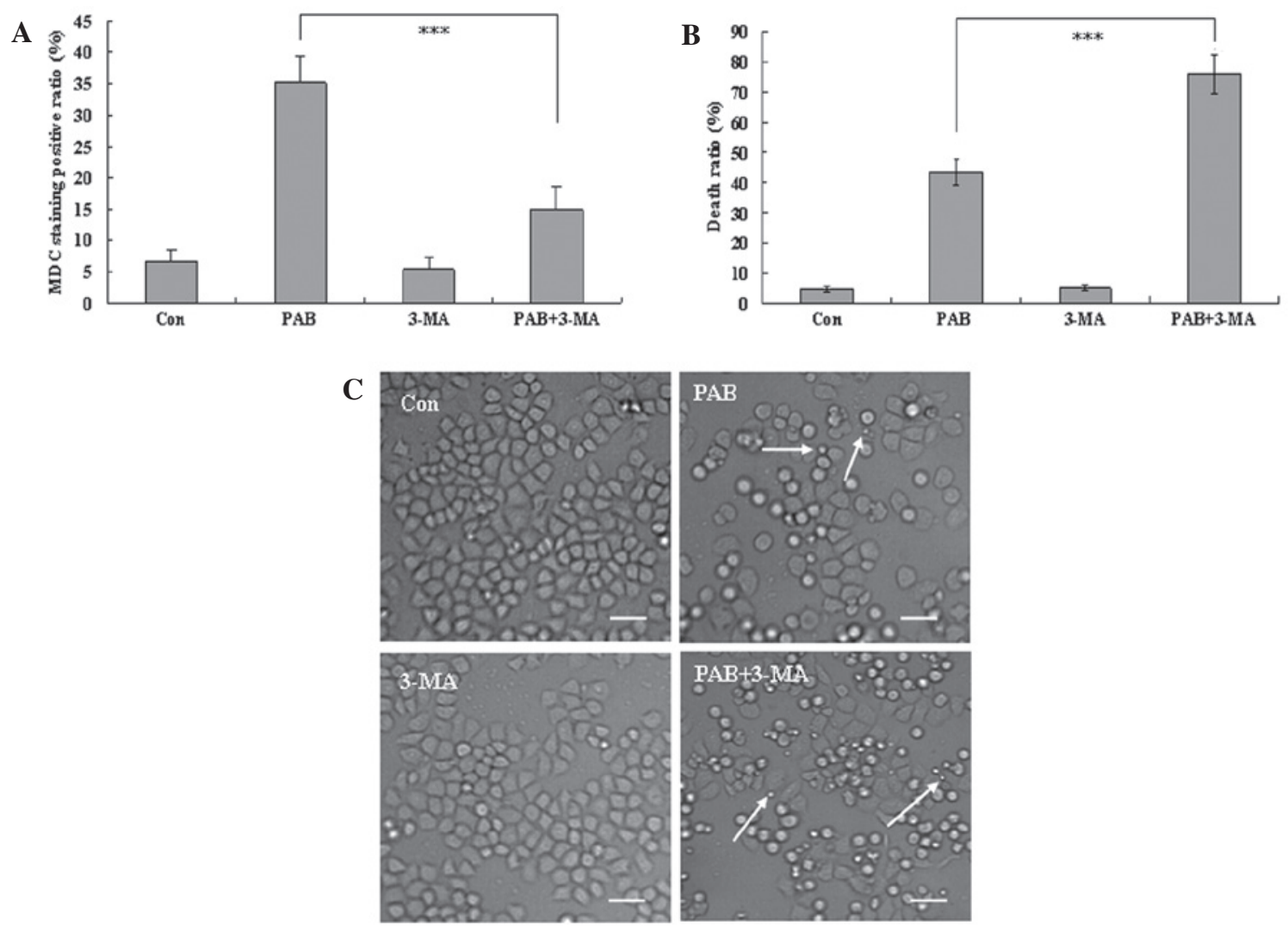

Figure 3. 3-MA inhibits autophagy and promotes cell death in PAB-treated MCF-7 cells. (A) The positive ratio of MDC staining (autophagic ratio) was analyzed quantitatively by flow cytometry. PAB increased MDC staining which was inhibited by 3 -MA. (B) $1 \times 10^{4} \mathrm{MCF}-7$ cells/well were incubated with $4 \mu \mathrm{M}$ $\mathrm{PAB}$ or $3 \mathrm{mM} 3-\mathrm{MA}$ for $36 \mathrm{~h}$ and growth inhibition was evaluated using the MTT assay. These findings indicated that 3-MA increased the efficacy of PAB in inducing cell death. Error bars $=$ mean \pm standard deviation, ${ }^{* * *} \mathrm{P}<0.001$. (C) 3 -MA in addition to PAB promoted cell death following treatment with $4 \mu \mathrm{M}$ PAB for $36 \mathrm{~h}$. Arrows indicate apoptotic bodies. Scale bar, $25 \mu \mathrm{m}$. All experiments were performed in triplicate. MDC, monodansylcadaverine; Con, control; PAB, pseudolaric acid B; 3-MA, 3-methyladenine. 
A
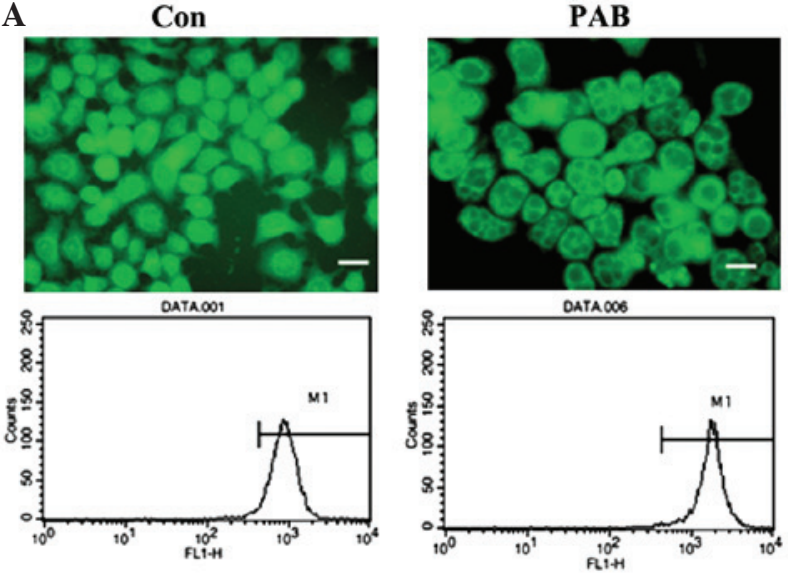

C
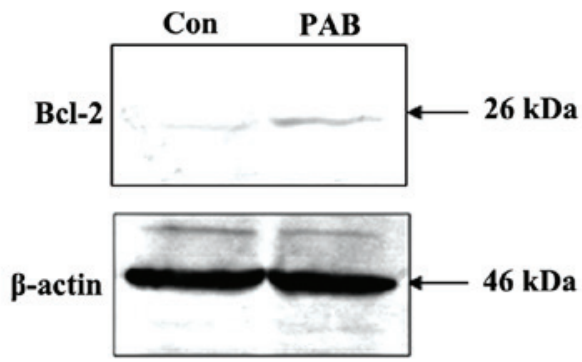

B

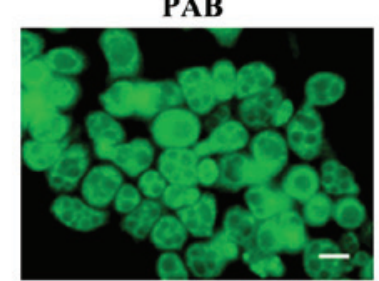

$26 \mathrm{kDa}$

D

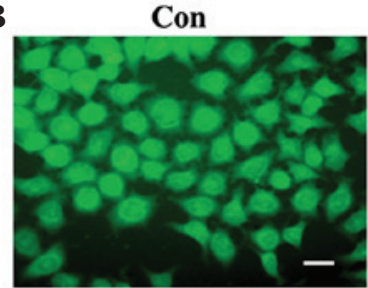

001
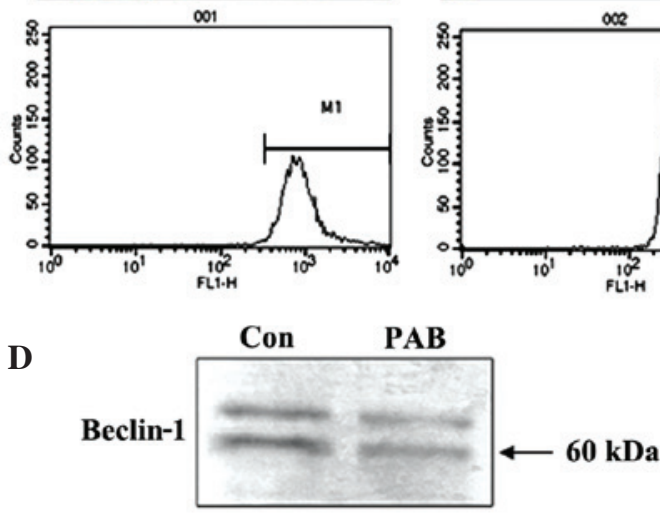

Bcl-2

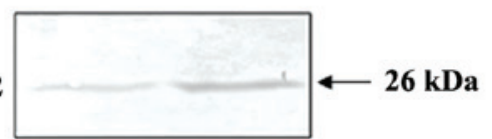

Figure 4. Mitochondrial profile related to autophagy at $36 \mathrm{~h}$ following PAB treatment. (A) Mitochondrial membrane potential was visualized by fluorescence microscopy and detected by flow cytometry with rhodamine 123 staining (scale bar, $25 \mu \mathrm{m}$ ), revealing that PAB did not affect mitochondrial membrane potential compared to the Con group. (B) Mitochondrial membrane potential was visualized by fluorescence microscope and detected by flow cytometry with rhodamine 123 staining after $60 \mu \mathrm{M}$ DP for $12 \mathrm{~h}$ (scale bar, $25 \mu \mathrm{m}$ ); DP decreased the mitochondrial membrane potential compared to the Con group. (C) Expression of Bcl-2 protein was analyzed by western blotting. $\beta$-actin was used as a loading control; PAB increased Bcl-2 expression compared to the Con group. (D) Binding of Bcl-2 and Beclin-1 demonstrated by western blotting for Beclin-1 protein expression; PAB decreased the binding of Bcl-2 with Beclin-1 compared to the Con group. Data are representative of three individual experiments $(n=3)$. Con, control; PAB, pseudolaric acid B; DP, dracorhodin perchlorate.

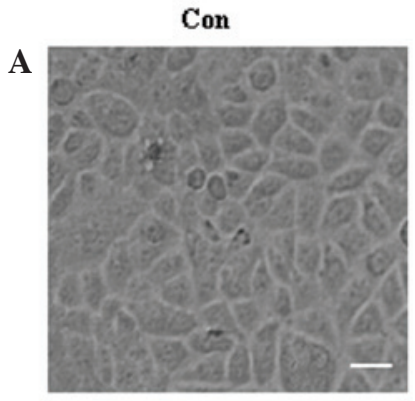

$\mathbf{B}$

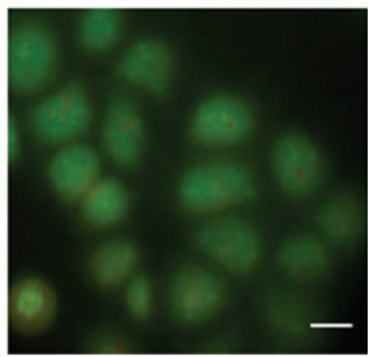

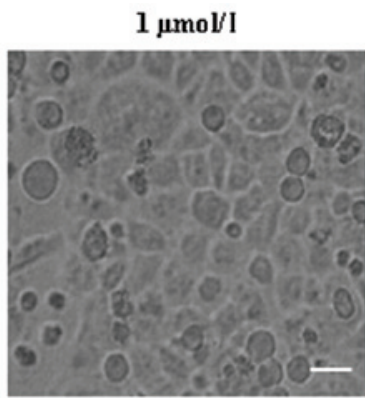

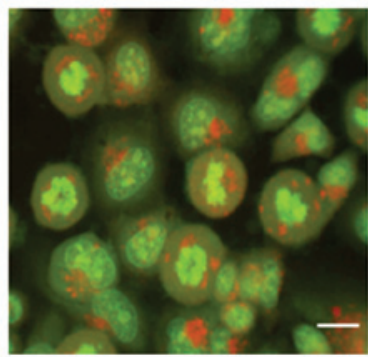

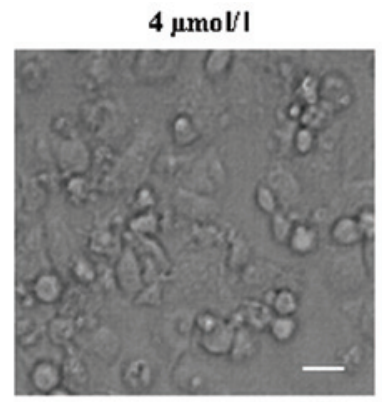

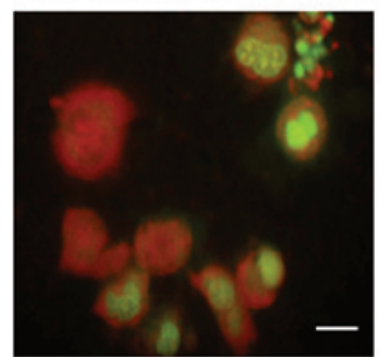

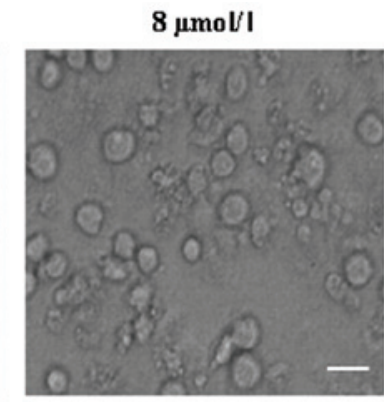

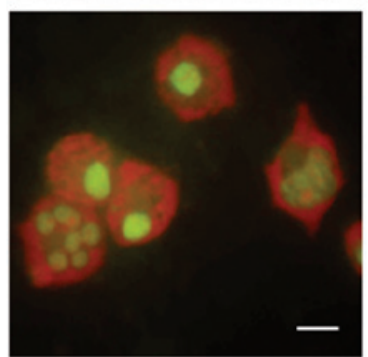

Figure 5. PAB increased autophagy and apoptosis in a dose-dependent manner. (A) Cell morphology was visualized by phase contrast microscope after 0,1 , 4 and $8 \mu \mathrm{M} \mathrm{PAB}$ treatment for $36 \mathrm{~h}$, revealing that PAB more effectively induced cell death with increasing doses (scale bar, $20 \mu \mathrm{m}$ ). (B) Acridine orange staining of autophagic vacuoles was visualized in MCF-7 cells treated with $0,1,4$ and $8 \mu \mathrm{M}$ PAB for $36 \mathrm{~h}$, indicating that PAB increased the number of autophagic vacuoles with increasing doses (scale bar, $10 \mu \mathrm{m}$ ). The experiments were performed in triplicate. Con, control.

cells and apoptotic bodies. Therefore, $3-\mathrm{MA}$ and $\mathrm{PAB}$ promoted the induction of cell death compared with PAB treatment alone (Fig. 3C), and autophagy appears to promote cell survival.
$P A B$ does not affect the mitochondrial membrane potential, and inhibits the binding of Bcl-2 and Beclin-1. Decreased mitochondrial membrane potential leads to cell death $(22,23)$. In the present study, fluorescence microscopic 
results demonstrated that the density of green fluorescence from rhodamine 123 staining following PAB treatment was same as control group, and flow cytometric analyses revealed that fluorescence density following rhodamine 123 staining did not differ between the PAB treatment group and the control group $(\mathrm{P}>0.05)$; thus PAB did not affect the mitochondrial membrane potential following $36 \mathrm{~h}$ of treatment (4 $\mu \mathrm{M}$; Fig. 4A). However, following $12 \mathrm{~h}$ of treatment with $60 \mu \mathrm{M}$ DP, the mitochondrial membrane potential decreased, indicating that the current method for analyzing the mitochondrial membrane was viable (Fig. 4B). Expression of Bcl-2 was investigated with regard to the mitochondrial membrane potential. PAB treatment was found to increase Bcl-2 expression (Fig. 4C). Therefore, it is possible that increased Bcl-2 sustained the mitochondrial membrane potential. It has been previously reported that the binding of Bcl-2 and Beclin-1 is important for promoting autophagy (20). The current immunoprecipitation analysis indicated that, following PAB treatment, the level of Beclin-1 bound with Bcl-2 was reduced; however, PAB increased Bcl-2 expression (Fig. 4D). Therefore, the lack of change in mitochondrial membrane potential following PAB treatment, may be associated with autophagy.

$P A B$ increased autophagy and apoptosis in a dose-dependent manner. To confirm whether autophagy is associated with cell death in MCF-7 cells, different doses of PAB $(0,1$, 4 or $8 \mu \mathrm{M}$ ) were used in an attempt to further stimulate autophagy. The appearance of increasing cell morphological changes, including floating cells and apoptotic bodies (Fig. 5A), indicated that cell apoptosis was increased with an increase of PAB dose. Meanwhile, a color change from green to red was observed with increasing PAB doses (Fig. 5B), indicating that autophagy was also increased. Therefore the results demonstrated a concurrent increase in apoptosis and autophagy when the dose of PAB was increased.

\section{Discussion}

A previous study demonstrated that PAB-induced apoptosis kills tumor cells; however, not all tumor cells were killed within a short time period (48 h), whereas over a longer period ( $\geq 72 \mathrm{~h}$ ) a proportion of cells became senescent and certain cells exhibited normal morphology following PAB treatment (7). Thus, the present study investigated why certain cells undergo apoptotic cell death and why other cells survive following PAB treatment.

The current study initially investigated whether autophagy occurred in PAB-treated cells to sustain cell survival by recycling cell material. The results indicated that PAB increased the expression of Beclin-1 and promoted the conversion of LC3-I to LC3-II. Furthermore, there was an increase in positive MDC and acridine orange staining (a marker of autophagy), whereas the autophagy inhibitor 3-MA abolished PAB-induced autophagy.

To confirm whether autophagy promotes cell survival, autophagy was inhibited with 3-MA, demonstrating that the ratio of cell death of $\mathrm{PAB}$ increases following treatment of 3-MA. This finding indicated that, in PAB-treated MCF-7 cells, inhibition of autophagy promotes cell death, thus providing an explanation for how cells could survive following PAB treatment. In previous study, the phenomena of inhibition of autophagy promoting cell death was also found in the murine fibrosarcoma L929 cell line (20). This is consistent with the current study; thus, inhibition of autophagy promoting cell death following PAB treatment appears to be a common characteristic, regardless of cell type and cell origin.

To further investigate the association between autophagy and cell death, the dose of PAB was increased, with the aim of increasing autophagy. The results demonstrated that autophagy increases with a concurrent increase in the dose of PAB. However, cell death was also increased. Therefore, we hypothesize that: i) Autophagy and cell death are activated by the same factor that is upregulated by PAB treatment, and ii) cell death is accompanied by autophagy, which decreases the effects of PAB. Therefore, combined application of PAB with an inhibitor of autophagy may increase the effectiveness of PAB treatment, which is important for the clinical application of PAB in breast cancer.

The mitochondrial membrane potential typically decreases during cell death $(22,23)$; however, the present study demonstrated that PAB did not affect mitochondrial membrane potential. This may explain why certain cells may survive following PAB treatment. Bcl-2 is associated with mitochondrial membrane potential and autophagy (20), and the present study demonstrated that expression of Bcl-2 increases following PAB treatment, possibly stabilizing the mitochondrial membrane potential. Furthermore, it has been reported that Bcl-2 inhibits autophagy through direct binding with Beclin-1 (24). By contrast, the PAB-induced Bcl-2 expression observed in the present study was also accompanied by enhanced autophagy. Therefore, the binding of Bcl-2 with Beclin-1 was analyzed, and the results demonstrated that the binding of Bcl-2 with Beclin-1 was inhibited following PAB treatment. Thus, we hypothesize that Bcl-2 may stabilize the mitochondrial membrane potential through binding with Bax or other proteins that decrease mitochondrial membrane potential and, consequently, is unable to bind with Beclin-1 to participate in autophagy.

In conclusion, the results of the current study demonstrate that autophagy protected breast cancer cells from death, thus, decreasing the anti-tumor effects of PAB. Considering our previous study using the L929 cell line (20), it is concluded that the development of PAB as anti-tumor medicine must include combination with an autophagy inhibitor. Although it remains unclear which other anti-tumor medicines are best able to inhibit autophagy to increase the effect of PAB, the current study provides a direction for research into medicine combination.

\section{Acknowledgements}

This study was supported in part by funded by grants from Jilin Provincial Science and Technology Department (no. 20140204004YY), National Natural Science Foundation of China (no. 81301416), the Chinese Ministry of Science and Technology (nos. 2012CB911100 and 2013ZX10001005), State Grade III Laboratory of Traditional Chinese Medicine, Immunology and Molecular Biology Laboratory and 
the Chinese Ministry of Education (no. IRT1016), and the Key Laboratory of Molecular Virology of Jilin Province (no. 20102209).

\section{References}

1. Li E, Clark AM and Hufford CD: Antifungal evaluation of pseudolaric acid B, a major constituent of Pseudolarix kaempferi. J Nat Prod 58: 57-67, 1995.

2. Wang WC, Lu RF, Zhao SX and Gu ZP: Comparison of early pregnancy-terminating effect and toxicity between pseudolaric acids A and B. Zhongguo Yao Li Xue Bao 9: 445-448, 1988 (In Chinese)

3. Pan DJ, Li ZL, Hu CQ, Chen K, Chang JJ and Lee KH: The cytotoxic principles of Pseudolarix kaempferi: Pseudolaric acid-A and -B and related derivatives. Planta Med 56 383-385, 1990.

4. Lv M, Lv M, Chen L, Qin T, Zhang X, Liu P and Yang J: Angiomotin promotes breast cancer cell proliferation and invasion. Oncol Rep 33: 1938-1946, 2015.

5. Tarasewicz E and Jeruss JS: Phospho-specific Smad3 signaling Impact on breast oncogenesis. Cell Cycle 11: 2443-2451, 2012.

6. Yu JH, Cui Q, Jiang YY, Yang W, Tashiro S, Onodera S and Ikejima T: Pseudolaric acid B induces apoptosis, senescence, and mitotic arrest in human breast cancer MCF-7. Acta Pharmacol Sin 28: 1975-1983, 2007.

7. Bursch W, Grasl-Kraupp B, Ellinger A, Török L, Kienzl H, Müllauer L and Schulte-Hermann R: Active cell death: Role in hepatocarcinogenesis and subtypes. Biochem Cell Biol 72: 669-675, 1994.

8. Kerr JF, Wyllie AH and Currie AR: Apoptosis: A basic biological phenomenon with wide-ranging implications in tissue kinetics. Br J Cancer 26: 239-257, 1972

9. Bursch W: The autophagosomal-lysosomal compartment in programmed cell death. Cell Death Differ 8: 569-581, 2001.

10. de Duve C and Wattiaux R: Functions of lysosomes. Annu Rev Physiol 28: 435-492, 1966.

11. Edinger AL and Thompson CB: Death by design: Apoptosis, necrosis and autophagy. Curr Opin Cell Biol 16: 663-669, 2004.
12. Klionsky DJ: The molecular machinery of autophagy: Unanswered questions. J Cell Sci 118: 7-18, 2005.

13. Leist $M$ and Jäättelä M: Four deaths and a funeral: From caspases to alternative mechanisms. Nat Rev Mol Cell Biol 2: 589-598, 2001.

14. Giansanti V, Torriglia A and Scovassi AI: Conversation between apoptosis and autophagy: 'Is it your turn or mine?'. Apoptosis 16: 321-333, 2011.

15. Lindqvist LM and Vaux DL: BCL2 and related prosurvival proteins require BAK1 and BAX to affect autophagy. Autophagy 10: 1474-1475, 2014.

16. Lockshin RA and Zakeri Z: Apoptosis, autophagy, and more. Int J Biochem Cell Biol 36: 2405-2419, 2004.

17. Biederbick A, Kern HF and Elsässer HP: Monodansylcadaverine (MDC) is a specific in vivo marker for autophagic vacuoles. Eur J Cell Biol 66: 3-14, 1995.

18. Seglen PO and Gordon PB: 3-Methyladenine: Specific inhibitor of autophagic/lysosomal protein degradation in isolated rat hepatocytes. Proc Natl Acad Sci USA 79: 1889-1892, 1982.

19. Zhang Y, Wu Y, Cheng Y, Zhao Z, Tashiro S, Onodera S and Ikejima T: Fas-mediated autophagy requires JNK activation in HeLa cells. Biochem Biophys Res Commun 377: 1205-1210, 2008.

20. Yu J, Li X, Tashiro S, Onodera S and Ikejima T: Bcl-2 family proteins were involved in pseudolaric acid B-induced autophagy in murine fibrosarcoma L929 cells. J Pharmacol Sci 107: 295-302, 2008.

21. Yu JH, Wang HJ, Li XR, Tashiro S, Onodera S and Ikejima T: Protein tyrosine kinase, JNK, and ERK involvement in pseudolaric acid B-induced apoptosis of human breast cancer MCF-7 cells. Acta Pharmacol Sin 29: 1069-1076, 2008.

22. Cregan SP, Dawson VL and Slack RS: Role of AIF in caspase-dependent and caspase-independent cell death. Oncogene 23: 2785-2796, 2004.

23. Cui Q, Yu JH, Wu JN, Tashiro S, Onodera S, Minami M and Ikejima T: P53-mediated cell cycle arrest and apoptosis through a caspase-3-independent, but caspase-9-dependent pathway in oridonin-treated MCF-7 human breast cancer cells. Acta Pharmacol Sin 28: 1057-1066, 2007.

24. Cheng P, Ni Z, Dai X, Wang B, Ding W, Rae Smith A, Xu L, Wu D, He F and Lian J: The novel BH-3 mimetic apogossypolone induces Beclin-1- and ROS-mediated autophagy in human hepatocellular carcinoma cells. Cell Death Dis 4: e489, 2013. 